\title{
POTENSI KEBAKARAN HUTAN DI IUPHHK-HT PT FINNANTARA INTIGA KABUPATEN SINTANG PROVINSI KALIMANTAN BARAT
}

\author{
The Potential of Forest Fire in IUPHHK-HT PT Finnantara Intiga Distric Sintang \\ Province Kalimantan Barat
}

Bambang Hero Saharjo ${ }^{1}$ dan Muhammad Yodhi Muhtady ${ }^{2}$

(Diterima Desember 2017/Disetujui Maret 2020)

\begin{abstract}
The forest fire potential based studied on rainfall and fire source of forest fire also forest fire controlling. The research was conducted from February to May 2016 in IUPHHK-HT PT Finnantara Intiga Sintang Distric Province Kalimantan Barat in the village of Sejirak and Ratu Damai. The objectives of this research are to analyze the level of vulnerability forest fire based on rainfall during 5 years, to analyze the source of forest fire and analyze the efforts of forest fire controlling in IUPHHK-HT PT Finnantara Intiga Sintang Distric Province Kalimantan Barat. The result showed that the average of yearly rainfall at 5 years was $3659 \mathrm{~mm}$. It can be categtorized into not fine front. While the largest potency of fire sources is come from the society in Sejirak village and Ratu Damai village, almost $80 \%$ the society in that village still using fire to do land clearing. Forest fire controlling in IUPHHK-HT PT Finnantara Intiga Sintang includes prevention, suppression and extinguishing.
\end{abstract}

Keyword : Rainfall, forest fire, Source fire, Sintang, West Kalimantan

\section{PENDAHULUAN}

Hutan merupakan sumberdaya alam yang tidak ternilai karena didalamnya terkandung keanekaragaman hayati sebagai sumber plasma nutfah, sumber hasil hutan kayu dan non-kayu,pengatur tata air, pencegah banjir dan erosi serta kesuburan tanah, perlindungan alam hayati untuk kepentingan ilmu pengetahuan, kebudayaan, rekreasi, pariwisata dan sebagainya. Hutan merupakan salah satu potensi alam terbesar di Indonesia, namun keberadaan hutan di Indonesia amat rentan terhadap gangguan terutama kebakaran hutan. kebakaran hutan merupakan kejadian pembakaran yang penjalarannya bebas pada areal yang tidak direncanakan serta mengkonsumsi bahan bakar alam dari hutan seperti serasah, rumput, ranting/cabang pohon mati, pohon mati yang tetap berdiri, logs, tunggak pohon, gulma, semak belukar, dedaunan dan pohon-pohon (Saharjo 2003). Kebakaran hutan dan lahan hampir setiap tahun terjadi di seluruh wilayah indonesia terutama saat musim kemarau dan kebakaran hutan terbesar terjadi pada Kebakaran tahun 1997/1998 yang menghanguskan 9,7 juta ha (Applegate dan Suyanto 2001).

Kebakaran hutan yang cukup besar seperti yang terjadi pada tahun 1997/98 menimbulkan dampak yang meliputi berbagai aspek, yaitu ekologi, ekonomi, sosial dan kesehatan bahkan psikologis dan politik (Suratmo 2003). Kerugian material kayu, non kayu dan hewan dan dampak negatif yang sampai menjadi isu global adalah

\footnotetext{
${ }^{1}$ Dosen Departemen Silvikultur, Fakultas Kehutanan Institut Pertanian Bogor

* Penulis korespondensi: e-mail: saharjobambangh@gmail.com

2 Mahasiswa Departemen Silvikultur, Fakultas Kehutanan Institut Pertanian Bogor
}

asap dari hasil pembakaran yang telah melintasi batas negara.

Ada dua faktor penyebab terjadi kebakaran hutan yakni faktor manusia dan faktor alam (Syaufina 2008). Pada dasarnya penyebab kebakaran hutan dan lahan di Indonesia hampir 99\% karena ulah manusia baik di sengaja maupun tidak di sengaja (unsur kelalaian) yaitu kegiatan konversi lahan menyumbang $34 \%$, perladangan berpindah $25 \%$, pertanian $17 \%$, proyek transmigrasi $8 \%$ dan hanya $1 \%$ yang disebabkan oleh alam (Pasaribu SM, Friyatno S. 2006).

Potensi kebakaran hutan di PT Finnantara Intiga dapat dikaji berdasarkan upaya pengendalian dan sumber penyebab kebakaran hutan serta faktor yang mempengaruhinya yaitu curah hujan. Sumber penyebab terjadinya kebakaran hutan dapat dikaji berdasarkan aktivitas masyarakat meliputi kegiatan persiapan lahan pertanian dan perladangan. Kajian potensi kebakaran hutan di PT finnatara intiga penting untuk mencegah terjadinya kebakaran hutan. Tujuan penelitian ini adalah menganalisis tingkat kerawanan kebakaran hutan berdasarkan data curah hujan 5 tahun terakhir (20112015), menganalisisi sumber api penyebab dan upaya penyebab kebakaran hutan di IUPHHK - HT PT Finnantara Intiga unit kerja Sintang Provinsi Kalimantan Barat.

\section{METODE PENELITIAN}

\section{Waktu dan Lokasi Penelitian}

Penelitian dilaksanakan pada bulan Februari sampai dengan Mei 2016 di IUPHHK - HT PT Finnantara Intiga unit kerja Sintang Kabupaten Sintang Provinsi Kalimantan Barat dengan desa penelitian Desa Sejirak dan Desa Ratu Damai. 


\section{Alat dan Bahan}

Alat yang digunakan dalam penelitian ini adalah laptop, kamera, kalkulator, alat tulis, perangkat komputer seperti Microsoft Word dan Microsoft Excel.

Bahan dan data yang diperlukan dalam penelitian yaitu data kebakaran hutan di PT Finanntara Intiga, daftar kuesioner dari masyarakat sekitar PT Finannantara Intiga Sintang terkait pembersihan lahan dan data curah hujan bulanan terakhir (2011-2015).

\section{Penentuan Lokasi Penelitian}

Penelitian ini dilaksanakan pada bulan februari sampai dengan april 2016 di areal IUPHHK - HT PT Finnantara Intiga Kabupaten Sintang Provinsi Kalimantan Barat. Pemilihan lokasi penelitian dilakukan secara sengaja (purposive sampling). Desa penelitian dipilih berdasarkan kedekatan jarak desa dan aksesibilitas mudah dijangkau.

\section{Penetapan Responden}

Responden ditentukan dengan menggunakan metode snowball, menurut Silalahi (2002) metode snowball adalah penunjukan terlebih dahulu seseorang yang dianggap mampu memberikan informasi (key informan) dan atas rekomendasinya dapat menunjuk responden lainnya untuk diwawancarai. Penunjukan key informan dilakukan oleh kepala desa pada masing-masing desa yang telah ditentukan sebagai lokasi penelitian. Jumlah responden minimal dalam penelitian sebanyak 30 orang untuk mewakili seluruh populasi (Singarimbun et a l1995).

\section{Pengumpulan Data}

Data yang digunakan dalam penelitian meliputi data primer dan data sekunder.

\section{Pengumulan data primer}

\section{Wawancara}

Pengumpulan data primer dilakukan dengan wawancara mendalam yang dilakukan peneliti terhadap pihak PT Finannantara Intiga dan masyarakat Desa Sejirak dan Desa Ratu Damai yang diminta pendapat dan tindakan yang dilakukan terkait kebakaran hutan. Pengumpulan data wawancara mengikuti metode Muhadjir (1992), yaitu peneliti mendatangi responden secara langsung dan mengambil kesempatan yang memudahkan.

\section{Observasi langsung}

Pengumpulan data dilakukan berdasarkan pengamatan langsung terhadap objek yang diteliti.

Tabel 1 Kelas kerawanan kebakaran hutan berdasarkan curah hujan

\begin{tabular}{lll}
\hline Kelas kerawanan & $\begin{array}{l}\text { Curah } \\
\text { (mm/tahun) }\end{array}$ & hujan \\
\hline Rawan sangat tinggi & $<500$ \\
Rawan sedang & $1000-1500$ & \\
Tidak rawan & $>2000$ & \\
\hline Sumber: Senticorini 2006 &
\end{tabular}

Informan dalam penelitian adalah pihak PT Finanntara Intiga Sintang dan Mayarakat Desa Sejirak dan Desa Ratu Damai.

\section{Pengumpulan data sekunder}

Data sekunder diperoleh melalui studi dokumen dan arsip. Data sekunder meliputi data kebakaran hutan 5 tahun terakhir ( 2011-2015) di PT Finnantara Intiga Sintang,data kondisi kawasan PT Finnantara Intiga Sintang, serta data curah hujan di PT Finnantara Intiga Sintang 5 tahun terakhir (2011-2015).

\section{Analisis Data}

Data dianalisis menggunakan metode deskriptif kualitatif yaitu dengan mendeskripsikan secara menyeluruh data yang didapat selama proses penelitian. Analisis deskriptif merupakan metode penelitian yang berusaha menggambarkan dan menginterpretasikan objek sesuai data yang dikumpulkan tanpa melakukan pengujian hipotesis (Best 1982 dalam sukardi 2004). Data curah hujan kemudian diklasifikasikan berdasarkan kelas kerawanan kebakaran hutan berdasarkan curah hujan tersaji pada Tabel 1 (Septicorini 2006).

Analisis sumber api penyebab terjadinya kebakaran hutan dilakukan dengan mengidentifikasi data hasil wawancara dan analisis upaya pengendalian kebakaran hutan di PT Finnantara Intigan Sintang. Data disajikan dalam bentuk narasi, tabel dan gambar berdasarkan data yang telah dikumpulkan selama penelitian.

\section{HASIL DAN PEMBAHASAN}

\section{Kondisi Umum Lokasi Penelitian}

\section{Lokasi IUPHHK-HT PT Finnantara Intiga Kabupaten Sintang}

Izin Usaha Pemanfaatan Hasil Hutan Kayu Hutan Tanaman Industri (IUPHHK-HTI) PT Finnantara Intiga berdasarkan Surat Keputusan Menteri Kehutanan Nomor 750/KPTS-II/1996,tanggal 2 Desember 1996 dengan luas areal konsesi seluas 299.700 Ha yang terbagi 3 yaitu Kabupaten Sanggau, Kabupaten Sekadau dan Kabupaten Sintang, Provinsi Kalimantan Barat.

Wilayah PT Finnantara Intiga Sintang secara geografis terletak pada posisi $0^{\circ} 00^{\prime} \mathrm{LU}-0^{\circ} 50^{\prime} \mathrm{LU}$ dan $110^{\circ} 30^{\prime}$ BT $-111^{\circ} 40^{\prime}$ BT. Menurut pembagian wilayah administrasi PT Finnantara Intiga Sintang meliputi Kecamatan Ketungau Hilir, Kecamatan Sepauk, ketungau Hulu, Ketungau tengah dan Kecamatan Tempunak.

Areal PT Finnantara Intiga berada pada lahan basah dan lahan kering dengan jenis tanah podsolik merah kuning, Organosol,Aluvial kelabu dan Podsolik. Lokasi areal PT Finnantara Intiga berada pada ketinggian 11-300 mdpl dengan lokasi datar. Berdasarkan sistem klasifikasi iklim Schmidt-Fergusson, areal IUPHHK-HT PT Finnantara Intiga termasuk tipe iklim A dengan curah hujan yang cukup tinggi mencapai rata-rata 3659 mm/tahun (RKU Finnantara Intiga 2015). Berdasarkan 
keberadaan tanaman HTI, pada desa di dalam areal konsensi teridentifikasi 37 desa yang telah terdapat tanaman HTI dan 24 desa belum terdapat tanaman HTI, sedangkan pada desa di luar areal konsensi teridentifikasi 3 desa yang telah terdapat tanaman HTI dan 2 desa belum ada tanaman HTI. Masyarakat desa sekitar areal (RKU Finnantara Intiga 2015).

\section{Desa Penelitian}

Desa Sejirak merupakan salah satu desa yang terletak disekitar areal konsesi PT Finnantara Intiga. Desa Sejirak terletak di Kecamatan Ketunggau Hilir, Kabupaten Sintang, Provinsi Kalimantan Barat. Desa Sejirak memiliki luas $109,85 \mathrm{~km}^{2}$. Desa Sejirak memiliki penduduk berjumlah 1440 jiwa.

Desa Ratu Damai terletak di Kecamatan Ketunggau Hilir, Kabupaten Sintang, Provinsi Kalimantan Barat. Desa Ratu Damai memiliki luas 140,65 km. Jumlah penduduk Desa Ratu Damai adalah 1103 jiwa dengan mata pencaharian umumnya bertani dan berladang.

\section{Potensi Kebakaran Hutan di PT Finnantara Intiga Sintang}

Potensi kebakaran hutan di PT Finnantara Intiga Sintang dianalisis dari faktor yang mempengaruhi yakni curah hujan dan sumber api yang menjadi penyebab terjadinya kebakaran hutan serta upaya pengendalian kebakaran hutan dari PT Finnantara Intiga. Potensi sumber api dikaji dari 2 pihak yakni dari pihak PT Finnantara Intiga dan aktivitas pertanian/perladangan masyarakat sekitar PT Finnantara Intiga.

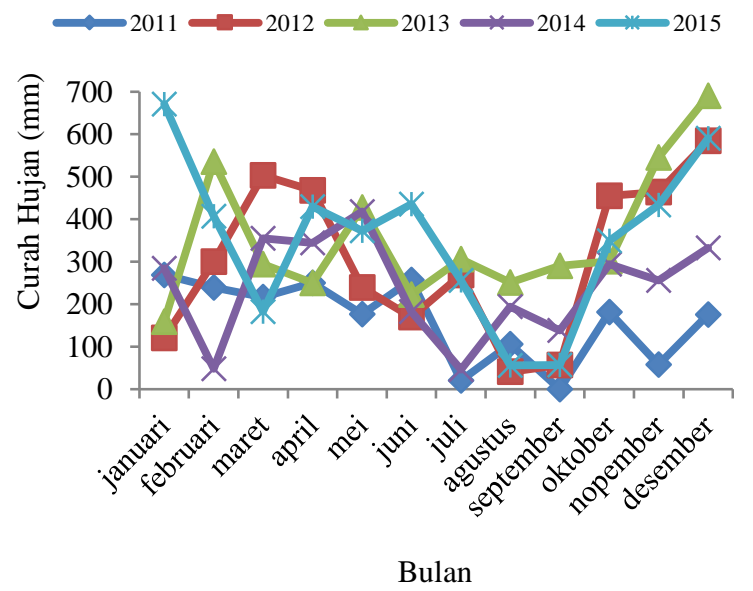

Gambar 1 Dinamika Curah Hujan Bulanan PT Finnantara Intiga Sintang Tahun 20112015

\section{Curah Hujan}

Curah hujan merupakan faktor iklim yang memiliki peran penting terjadinya kebakaran hutan karena menentukan akumulasi bahan bakar. Faktor curah hujan ini juga penting dilihat pada bulan-bulan apa yang termasuk curah tinggi dan curah hujan rendah (Purbowaseso 2004).

Berdasarkan sistem klasifikasi iklim SchmidtFergusson, PT Finnantara Intiga termasuk tipe iklim A dengan curah hujan yang cukup tinggi mencapai rata-rata $3659 \mathrm{~mm} /$ tahun. Curah hujan bulanan 5 tahun terakhir (2011-2015) di PT finnantara Intiga Sintang memiliki curah hujan terendah pada bulan Juli tahun 2011 dengan curah hujan 20,93 mm, sedangkan curah hujan tertinggi yaitu bulan Desember tahun 2013 dengan curah hujan sebesar 690,1 mm (Gambar 1).

Kebakaran hutan yang terjadi di PT Finnantara Intiga Sintang terjadi pada bulan Juli-September dengan frekuensi 6 kali terjadinya kebakaran hutan selama 5 tahun terakhir. Peningkatan kebakaran hutan terjadi pada bulan-bulan dengan curah hujan yang rendah (kurang dari $60 \mathrm{~mm}$ ) (Syaufina 2008).

Curah hujan 5 tahun terakhir di PT Finnantara Intiga Sintang yang memiliki curah hujan tahunan terendah pada tahun 2011 sebesar 2026,03 mm dan curah hujan tertinggi pada tahun 2013 sebesar 4272,05 mm (Gambar 2). Tahun 2011 juga merupakan kebakaran hutan paling luas selama 5 tahun terakhir dengan luas lahan terbakar seluas 19,69 Ha di PT Finnantara Intiga Sintang dan yang terendah pada tahun 2012 denagn luas lahan yang terbakar seluas 2,47 Ha (Tabel 2). Berdasarkan klasifikas kelas kerawanan kebakaran hutan berdasarkan curah hujan maka PT Finnantara Intiga Sintang memiliki tingkat kerawanan yang rendah atau tidak rawan terhadap kebakaran hutan dengan curah hujan tahunan sebesar 3659/tahun.

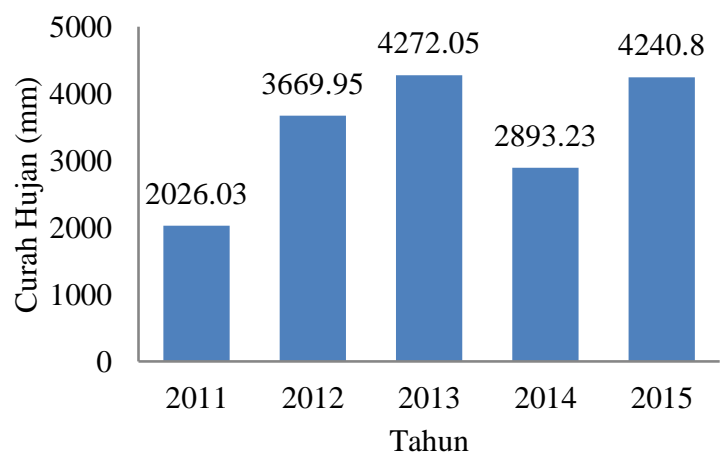

Gambar 2 Jumlah Curah Hujan PT Finnantara Intiga Sintang Tahun 2011-2015

Tabel 2 Data luas lahan terbakar PT Finnantara Intiga Tahun 2011-2015

\begin{tabular}{ccccccccccccc}
\hline \multirow{2}{*}{ Tahun } & \multicolumn{10}{c}{ Bulan } \\
\cline { 2 - 11 } & 1 & 2 & 3 & 4 & 5 & 6 & 7 & 8 & 9 & 10 & 11 & 12 \\
\hline 2011 & - & - & - & - & - & - & - & - & 19,69 & - & - \\
\hline 2012 & - & - & - & - & - & - & - & - & 2,47 & - & - & - \\
\hline 2013 & - & - & - & - & - & - & - & 2,89 & - & - \\
\hline 2014 & - & 5,9 & - & - & - & - & 3,42 & - & - & - \\
\hline 2015 & - & - & 0,77 & - & - & - & 0,77 & - & 0,96 & - & - \\
\hline
\end{tabular}

Sumber : Data luas lahan PT Finnantara Intiga Tahun 2011-2015 
Kejadian kebakaran hutan tertinggi pada tahun 2015 dengan frekuensi 3 kali dengan luas total lahan yang terbakar 2,5 Ha (Tabel 2). Kebakaran hutan PT Finnantara Intiga Sintang pada tahun 2011 luas lahan yang terbakar seluas 19,69 Ha yang merupakan

kebakaran hutan paling luas dalam 5 tahun terakhir dan luas lahan yang terbakar terendah terjadi tahun 2012 seluas 2,47 Ha yang terjadi pada bulan-bulan dengan curah hujan rendah (Gambar 3).

\section{Pembersihan Lahan Oleh PT Finnantara Intiga Sintang}

PT Finnantara Intiga Sintang dalam pembersihan lahan dilakukan secara mekanis menggunakan tanpa menggunakan api atau Penyiapan Lahan Tanpa Bakar (PLTB). Persiapan lahan tanpa bakar merupakan kegiatan mewujudkan pra kondisi optimal untuk keperluan penanaman, memelihara kesuburan tanah, mempermudah penanaman dan mengurangi persaingan gulma. Persiapan lahan tanpa bakar meliputi bukanjalur, sebar serasah (spreading).

\section{Pembersihan Lahan Oleh Masyarakat Sekitar PT Finnantara Intiga Sintang}

Masyarakat Desa Sejirak dan Ratu Damai adalah masyarakat asli (Suku Dayak) dan masyarakat transmigran yang sudah mendiami kawasan konsesi sebelum PT Finnantara Intiga Sintang masuk pada tahun 1996. Pada umumnya, mata pencaharian masyarakat Desa Sejirak dan Ratu Damai adalah berladang.

Ladang yang dimiliki para peladang merupakan ladang turun-termun 76,7\% masyarakat Desa Sejirak dan

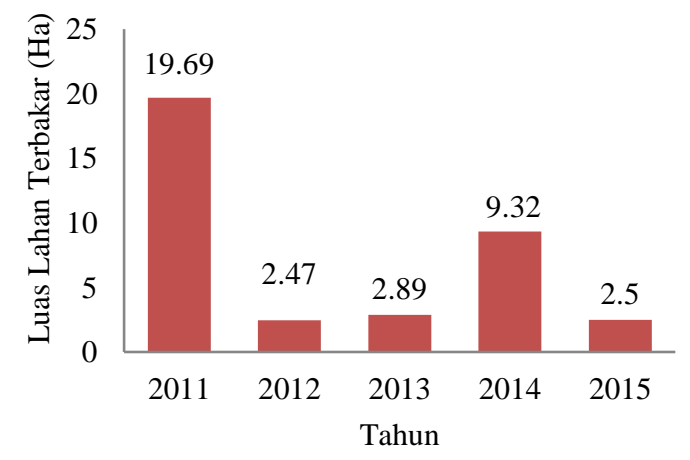

Gambar 3 Luas Lahan Terbakar PT Finnantara Intiga Sintang Periode 2011-2015
86,7\% masyarakat Desa Ratu Damai melakukan perladangan berpindah, sedangkan $23,3 \%$ masyarakat Desa Sejirak dan 13,3\% masyarakat Desa Ratu Damai yang berladang menetap (Gambar 4). Pembukaan lahan untuk perladangan tersebut umumnya sangat terbatas dan terkendali karena telah mengikutu aturan turun-temurun (Dove 1998 dalam Prasetyo 2007).

Pembersihan lahan yang dilakukan oleh masyarakat Desa Sejirak dan Desa Ratu Damai dibedakan menjadi 2 jenis yaitu dengan cara bakar dan tanpa bakar. Berdasarkan data kuesioner dan wawancara 93,3\% masyarakat Desa Sejirak melakukan pembersihan lahan dengan cara bakar dan 6,67.\% yang tanpa bakar saat pembersihan lahan.

Masyarakat Desa Ratu Damai sebanyak 86,7\% melakukan pembersihan dengan cara bakar dan 13,3\% yang tanpa bakar saat pembersihan lahan. Pembersihan lahan dengan cara bakar lebih disukai masyarakat karena lebih efisien dari segi waktu dan biaya serta mudah dalam pelaksaananya. Selain mudah,murah dan cepat, abu sisa pembakaran dapat dijadikan pupuk untuk tanaman. Lahan yang akan dibersihkan dengan cara bakar berkisar

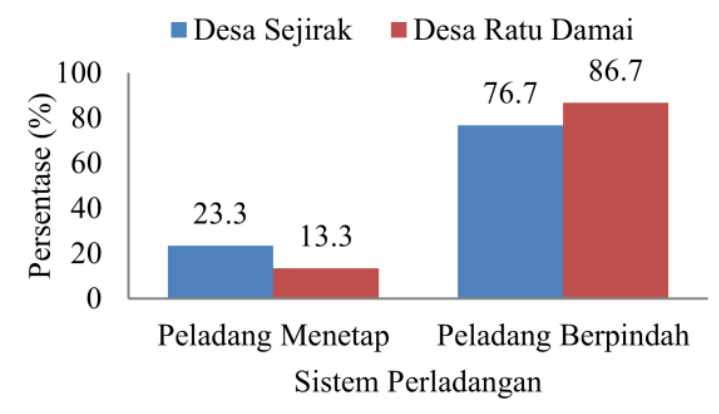

Gambar 4. Persentase perladangan masyarakat Desa Sejirak dan Desa Ratu Damai

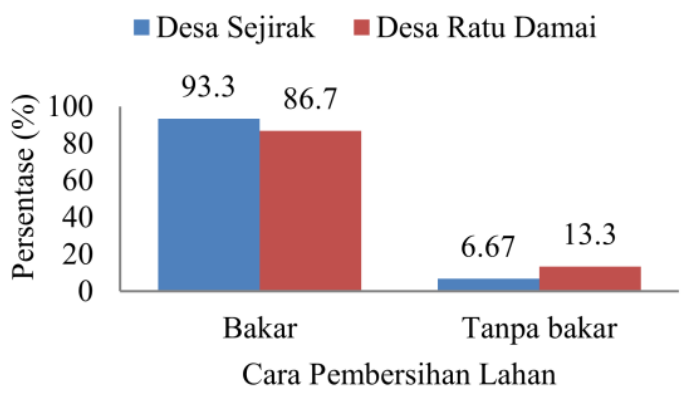

Gambar 5 Persentase cara pembersihan lahan oleh masyarakat Desa Sejirak dan Ratu Damai

Tabel 3 Luas lahan garapan masyarakat Desa Sejirak dan Desa Ratu Damai

\begin{tabular}{cccccc}
\hline \multirow{2}{*}{ No. } & Rata-rata Luas Lahan yang dibakar & \multicolumn{2}{c}{ Desa Sejirak } & \multicolumn{2}{c}{ Desa Ratu Damai } \\
\cline { 3 - 5 } & & $\begin{array}{c}\text { Jumlah } \\
\text { responden }\end{array}$ & Persentase & $\begin{array}{c}\text { Jumlah } \\
\text { responden }\end{array}$ & Persentase \\
\hline 1 & $0,5-1 \mathrm{Ha}$ & 25 & 83,33 & 28 & 93,33 \\
2 & $1-3 \mathrm{Ha}$ & 5 & 16.67 & 2 & 6,67 \\
3 & $>3 \mathrm{Ha}$ & 0 & 0 & 0 & 0 \\
\hline
\end{tabular}

Tabel 4 Waktu masyarakat membakar ladang

\begin{tabular}{cccccc}
\hline \multirow{2}{*}{ No. } & \multirow{2}{*}{ Waktu } & \multicolumn{2}{c}{ Desa Sejirak } & \multicolumn{2}{c}{ Desa Ratu Damai } \\
\cline { 3 - 6 } & Pumlah & Persentase & $\begin{array}{c}\text { Jumlah } \\
\text { responden }\end{array}$ & Persentase \\
\hline 1 & Pagi-Siang & 7 & 23,33 & 9 & 30 \\
2 & Sore-Malam & 23 & 76,67 & 21 & 70 \\
\hline
\end{tabular}


0,5 sampai 3 Ha (Tabel 2). Lokasi lahan yang bersebelahan dengan areal perusahaan dalam pembersihan lahan yang dilakukan masyarakat menggunakan api berpotensi menimbulkan sumber api yang dapat merambat ke areal perusahaan.

Berdasarkan hasil wawancara masyarakat dalam melakukan pembersihan lahan dengan api sebanyak 76,67\% masyarakat Desa Sejirak dan $70 \%$ masyarakat Desa ratu Damai melakukan pembakaran lahan pada sore-malam hari (Tabel 4).

Pembersihan lahan diawali dengan menebas semak belukar dan sisa tanaman pada ladang masyarakat, kemudian sampah hasil penebasan dikumpulkan pada satu titik untuk dibakar. Masyarakat Desa Sejirak dan Ratu Damai membuat sekat bakar sebelum proses pembakaran lahan berkisar 1,5-2 m untuk mencegah api merambat ke area lain.

Sumber api penyebab kebakaran hutan berdasarkan wawancara dengan masyarakat, kebakaran hutan disebabkan karena kelalaian manusia dalam menggunakan api disekitar kawasan hutan yang dapat menimbulkan api liar ( 40\%) akibat masyarakat yang membuang puntung rokok sembarangan disekitar kawasan hutan dan bara api yang masih menyala setelah pembersihan lahan dan api loncat $(60 \%)$ yang terjadi saat proses pembakaran lahan (Gambar 6).

\section{Pengendalian Kebakaran Hutan di PT Finnatara Intiga Sintang}

Pengendalian kebakaran hutan ialah setiap usaha yang dilakukan,baik bersifat preventif maupun represif untuk menekan kerusakan hutan akibat kebakaran hutan. Pengendalian Kebakaran Hutan mencakup 3 komponen kegiatan yaitu pencegahan, pemadaman dan penanganan pasca kebakaran (PP No. 45 tahun 2004).

\section{Pencegahan Kebakaran Hutan}

Pencegahan kebakaran hutan diberikan kepada masyarakat dengan harapan agar masyarakat dapat berkontribusi dalam mencegah kebakaran hutan. Tabel 5 menunjukan kegiatan pencegahan kebakaran hutan di Desa Sejirak sebesar $40 \%$ dan di Desa Ratu Damai

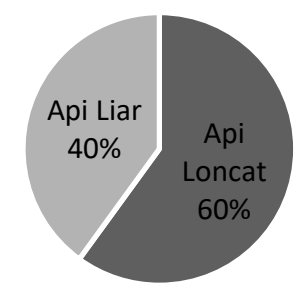

Gambar 6 Sumber api penyebab kebakaran hutan sebesar 30\% masyarakat mengetahui adanya kegiatan penyuluhan/sosialisasi. Penyuluhan dilakukan untuk memberi informasi terhadap masyarakat bahaya dari kebakaran hutan dan penyuluhan ini juga bertujuan untuk menjalin komunikasi yang baik dengan masyarakat.

Penyuluhan tidak langsung juga dilakukan oleh PT Finnantara Intiga Sintang dengan memasang papan peringatan di tepi jalan. Papan peringatan berfungsi untuk memperingati masyarakat yang akan memasuki hutan dan hendak berhati-hati dalam penggunaan api di dalam hutan ( Gambar 7).

Masyarakat Desa Sejirak sebesar 60\% dan masyarakat Desa Ratu Damai sebesar 70\% pernah melihat adanya papan peringatan tersebut namun papan peringatan dipasang hanya pada musim-musim kebakaran hutan seperti bulan Juli-September, setelah itu papan peringatan rusak dan bahkan hilang. Pencegahan kebakaran hutan lainnya yang dilakukan PT Finnantara Intiga Sintang ialah penyediaan dan perawatan sarana dan prasarana pencegahan kebakaran hutan ,perekrutan anggota Regu Pemadam Kebakaran (RPK) dan Masyarakat Peduli Api (MPA), pelatihan kebakaran hutan untuk karyawan dan patroli rutin pencegahan kebakaran hutan.

\section{Pemadaman Kebakaran Hutan}

Metode pemadaman yang digunakan adalah pemadaman secara langsung. Pemadaman secara langsung adalah aktivitas secara langsung yang berkesinambungan untuk mendinginkan, mengibas, memukul, memindahkan bahan bakar atau memadamkan

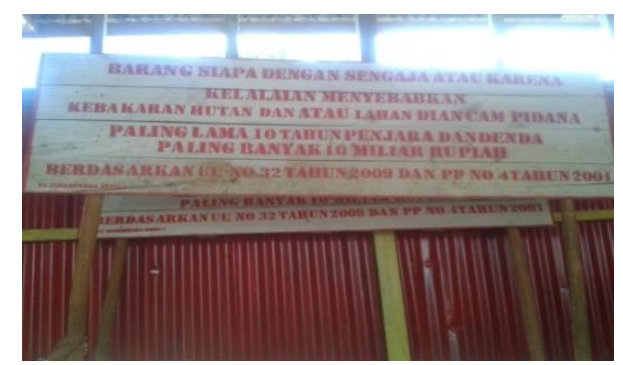

Gambar 7 Papan peringatan PT Finnantara Intiga Sintang

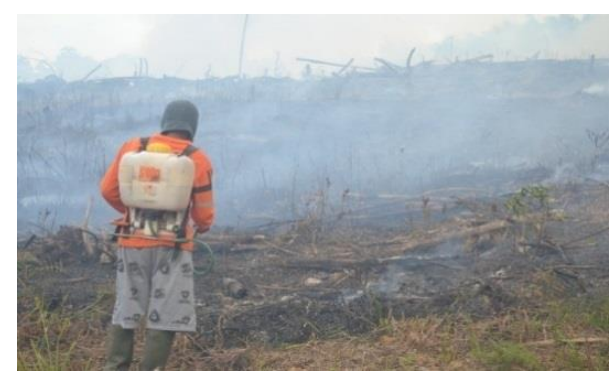

Gambar 8 Pemadaman Kebakaran Hutan di PT Finnantara Intiga Sintang

Tabel 5 Kegiatan pencegahan kebakaran hutan di PT Finnantara Intiga Sintang

\begin{tabular}{|c|c|c|c|c|c|}
\hline \multirow[b]{2}{*}{ No. } & \multirow[b]{2}{*}{$\begin{array}{c}\text { Kegiatan Pencegahan } \\
\text { Kebakaran Hutan }\end{array}$} & \multicolumn{2}{|c|}{ Desa Sejirak } & \multicolumn{2}{|c|}{ Desa Ratu Damai } \\
\hline & & $\begin{array}{c}\text { Jumlah } \\
\text { responden }\end{array}$ & Persentase & $\begin{array}{c}\text { Jumlah } \\
\text { responden }\end{array}$ & Persentase \\
\hline 1 & Penyuluhan/sosialisasi & 12 & 40 & 9 & 30 \\
\hline 2 & Papan peringatan & 18 & 60 & 21 & 70 \\
\hline
\end{tabular}


api, dengan syarat api kecil, bahan bakar sedikit dan kebakaran permukaan (Purbowaseso 2004).

Pemadaman kebakaran hutan dilakuakn secara langsung dan membuat ilaran api dengan menggunakan peralatan kebakaran hutan seperti pemukul api (kepyok), kapak, cangkul, semprotan air dan jika kebakaran besar menggunakan mobil tangki air.

\section{Penanganan Pasca kebakaran}

Penanganan pasca kebakaran hutan di PT Finnantara Intiga Sintang yang dilakukan dengan pembuatan laporan tertulis. Pengumpulan data terkait luas lahan yang terbakar, jenis-jenis vegetasi,nilai kerugian akibat kebakaran hutan serta penyebab kebakaran hutan, Rehabilitasi kawasan bekas terbakar dan koordinasi dengan penegak hukum.

\section{SIMPULAN DAN SARAN}

\section{Simpulan}

Potensi kebakaran hutan di PT Finnantara Intiga Sintang tergolong rendah. Rata-rata curah hujan per tahun sebesar $3659 \mathrm{~mm} /$ tahun yang termasuk dalam tingkat tidak rawan terhadap kebakaran hutan. Potensi sumber api dari pihak perusahaan tergolong rendah karena PT Finnantara Intiga Sintang menerapkan sistem mekanis dalam pembersihan lahan/Penyiapan Lahan Tanpa Bakar (PLTB). Potensi sumber api terbesar dari masyarakat sekitar perusahaan, dimana hampir setiap keluarga menerapkan pembersihan lahan dengan cara bakar dan perladangan berpindah. Pengendalian kebakaran hutan yang dilakukan PT Finnantara Intiga Sintang yaitu pencegahan, pemadaman dan penanganan pasca kebakaran hutan.

\section{Saran}

Penyuluhan/sosialisasi terkait kebakaran hutan perlu dilakukan secara berkala (3 bulan sekali), agar masyarakat paham dan mengerti bahaya akibat kebakaran hutan dan rutin diadakan pertemuan yang dapat menjalin komunikasi yang lebih baik antara masyarakat desa dan perusahaan. Apabila ketersediaan dan makan lebih baik lagi apabila diberikan bonus intensif terhadap masyarakat yang dapat mencegah terjadi kebakaran hutan di desa-desa sekitar perusahaan. Selain itu, perlu ditingkatkan perawatan terhadap sarana dan prasaran pengendalian kebakaran hutan di PT Finnantara Intiga Sintang.

\section{DAFTAR PUSTAKA}

[BPS]. Badan Pusat Statistik. Ketunggau Hilir Dalam Angka 2013.Jakarta(ID): Badan Pusat Statistik.

Dove RM 1988. Sistem Perladangan Di Indonesia : Suatu Studi Kasus Dari Kalimantan Barat. Ypgyakarta (ID). Gadjah Mada Press.

Handoko. 1994. Klimatologi Dasar. Jakarta(ID): Pustaka Jaya.

Muhadjir N. 1992. Metodologi Penelitian Kualitatif. Telaah Positivistik, Rasionalistik, Phenomenologik, Realisme Metaphisik. Yogyakarta (ID): Penerbit Rake Sarasin.

Pasaribu SM, Friyatno S. 2006. Memahami penyebab kebakaran hutan dan lahan serta upaya penanggulangannya : kasus di provinsi Kalimantan Barat. Bogor (ID).Pusat Analisis Sosial Ekonomi dan Kebijakan Pertanian.

Peraturan Pemerintah Republik Indonesia Nomor 45 Tahun 2004. Tentang Perlindungan Hutan. Jakarta (ID): Sekretariat Jendral Departemen Kehutanan.

Purbowaseso B. 2004. Pengendalian Kebakaran Hutan. Jakarta (ID): PT. Rineka

Cipta.

Saharjo BH. 2003. Sumber Api. Pengetahuan Dasar Pengendalian Kebakaran Hutan. Bogor (ID): Fakultas Kehutanan IPB. Hlm 147-149.

Septicorini EP. 2006. Studi penentuan tingkat kerawanan kebakaran hutan di Kabupaten Ogan Komering Hilir Propinsi Sumatera Selatan [skripsi]. Bogor (ID): Fakultas Kehutanan, Institut Pertanian Bogor.

Singarimbun, Masri, Sofian E. 1995. Metode Penelitian Survei. Jakarta (ID): LP3S.

Sugioyo. 2005. Memahami Penelitian Kualitatif. Bandung(ID): CV.Alfabeta.

Sukardi. 2004. Metodologi Penelitian Pendidikan. Jakarta (ID): Bumi Aksara.

Suratmo FG, Husaeni EA., Jaya INS. 2003. Pengetahuan Dasar Pengendalian Kebakaran Hutan. Bogor: Fakultas Kehutanan IPB.

Suyanto S dan Applegate G. 2001. Akar penyebab dan dampak kebakaran hutan dan lahan di Sumatera. Di dalam: Suyanto S, Permana RP, Setjono D dan Applegate G, editor. Prosiding Seminar Sehari Hasil Penelitian Kebakaran Hutan dan Lahan di Sumatera. Bogor (ID): ICRAF

Syaufina L. 2008. Kebakaran Hutan dan Lahan di Indonesia. Malang (ID): Bayumedia. 